\section{ACUTE PULMONARY THROIMBOEMBOLISIM IN COVID-19 PATIENTS: EVALUATION USING CT PULMONARY ANGIOGRAPHY}

KEY WORDS: COVID-19, CTPA (Computed Tomography Pulmonary Angiography), thromboembolism

\section{Dr. Ajay Gupta}

\section{Dr. Krati Jain*}

\section{Dr. Manish} Bhagat
Professor, Department of Radiodiagnosis, SAIMS Indore, Madhya Pradesh, India.

Resident, Department of Radiodiagnosis, SAIMS Indore, Madhya Pradesh, India. *Corresponding Author

Professor\& HOD, Department of Radiodiagnosis, SAIMS Indore, Madhya Pradesh, India.

Introduction- COVID-19 disease has been associated with pro thrombotic state and endothelial damage resulting into thromboembolic events ranging from venous thrombosis of lower limbs to pulmonary thrombo-embolism and subsequently pulmonary infarctions. Computed tomographic pulmonary angiography (CTPA) was the standard of care at our institute for evaluation of patients with suspected pulmonary embolism. It plays a key role in its confirmatory diagnosis, defining its extent and thereby helping in better management.

E Materials and Methods- A Retrospective study was done in Sri Aurobindo Medical College and Post graduate Institute, Indore, Madhya Pradesh, India and was approved by the hospital ethical committee. The study was done on 300 COVID19 patients with clinically suspected pulmonary thromboembolism who underwent CTPA between the months of January 2021 and October 2021 . The scans were analysed by experienced radiologists.

Results- Through our study we found that approx. $13.7 \%$ patients had pulmonary thromboembolism and it was seen in patients with moderate to severe lung involvement.

Conclusion- Through this study we have tried to assess the presence pulmonary thromboembolism using CTPA and have also tried to establish its relationship with percentage of lung involvement on CT.

Aims and Objectives - To assess for the presence of acute pulmonary thromboembolism in COVID 19 patients using CTPA and to establish its relationship with severity of lung involvement on CT in a single institute in Central India during a span of six months.

\section{INTRODUCTION-}

The causes of morbidity and mortality due to COVID-19 are multiple and multifactorial, with respiratory failure from pneumonia and subsequently acute respiratory distress syndrome(ARDS) are the chief contributors. Another most important cause of respiratory distress and mortality is the presence of thromboembolic disease. Pulmonary thromboembolism has been found to be a major factor worsening the patient prognosis. ${ }^{[1]}$

Among the pathological investigations used the diagnostic sensitivity of the D-dimer test has been high but it cannot define the vasculature involved. On the other hand CTPA not only accurately identifies the presence of pulmonary thromboembolism, it also helps to define the extent of the disease and on CT we can also find the percentage of lung involvement as well as look for pulmonary infarction. ${ }^{[2,3]}$

In completely occluding acute pulmonary embolism the affected artery is often enlarged while in partially occluding ones, the embolus is often centrally located. In few cases the embolus may be eccentrically located where it tends to form acute angles with the vessel wall. ${ }^{[4]}$

Knowledge on COVID 19 related disease processes is still evolving. Unfortunately, there is limited information on the epidemiology and the exact pathophysiologic and molecular processes underlying COVID-19-associated thromboembolic disease due to lack of large prospective studies. ${ }^{[5]}$

The most widely accepted pathogenesis is that the virus binds to the the ACE-2 receptors on endothelial cells, especially within kidney heart, lung, and liver resulting in endothelial damage leading to a prothrombotic state which ultimately leads to processes like deep venous thrombosis, myocardial infarction, end organ infarcts, pulmonary thromboembolism, stroke, disseminated intravascular coagulation etc. ${ }^{[6]}$ Imaging (CTPA) thereby plays a key role in the diagnosis of the pulmonary thromboembolic disease and thereby facilitating its prompt management.

\section{MATERIALS AND METHOD-}

A Retrospective study was done in Sri Aurobindo Medical College and Post graduate Institute, Indore, Madhya Pradesh, India and was approved by the hospital ethical committee. The study was done on 300 COVID-19 patients with clinically suspected pulmonary thromboembolism who underwent CTPA between the months of January 2021 and October 2021.

Patients with history of hypersensitivity to intravenous contrast agents or deranged renal functions or patients who were not willing to undergo CTPA or not willing to be part of the study were excluded from the study.

Informed written consent was taken from the patient or patients relatives before subjecting the patient to scanning. CT scanning was performed using Single source 64 Slice CT scanner (Somatom Definition; Siemens Medical Solutions, Germany). CT pulmonary angiography was performed using non-ionic contrast media. The images were then transferred to a dedicated online workstation Multimodality Work Place (MMWP) (SIEMENS SOLUTIONS) for image post-processing techniques.

The scans were analysed by experienced radiologists and the findings were systematically recorded.

\section{OBSERVATIONS AND RESULTS-}

Table 1-shows age distribution of the study population

\begin{tabular}{|l|l|}
\hline Age group & Percentage \\
\hline $21-40$ yrs & 40.3 \\
\hline $41-60$ yrs & 23.8 \\
\hline $61-70$ yrs & 33 \\
\hline $71-90$ yrs & 2.9 \\
\hline
\end{tabular}

Maximum percentage of patients belonged to 21-40 years of age followed by 41-60 years age group. No patient was under 20 years of age. 
Table 2- shows percentage of lung involvement in different age groups.

\begin{tabular}{|l|l|l|l|l|}
\hline $\begin{array}{l}\text { Age } \\
\text { group }\end{array}$ & $\begin{array}{l}<25 \% \\
\text { involvement }\end{array}$ & $\begin{array}{l}25-50 \% \\
\text { involvement }\end{array}$ & $\begin{array}{l}50-75 \% \\
\text { involvement }\end{array}$ & $\begin{array}{l}>75 \% \\
\text { involvement }\end{array}$ \\
\hline $21-40$ yrs & 20.4 & 38.6 & 20.4 & 20.4 \\
\hline $41-60$ yrs & 11.5 & 50 & 15.3 & 23 \\
\hline $61-70$ yrs & 25 & 36.1 & 27.7 & 11.1 \\
\hline $71-90$ yrs & 0 & 66.7 & 33.3 & 0 \\
\hline
\end{tabular}

In 21-40 yrs age group maximum patients had lung involvement between $25-50 \%$ and equal percentage of patients had $<25,50-75$ and $>75 \%$ involvement.

In 41-60 yrs age group maximum patients had lung involvement between $25-50 \%$ followed by $>75 \%$ involvement.

In 61-70 yrs age group maximum patients had lung involvement between $25-50 \%$ followed by $50-75 \%$ involvement.

In 71-90 yrs age group maximum patients had lung involvement between $25-50 \%$ followed by $50-75 \%$ involvement.

Table 3-shows gender distribution of the study population

\begin{tabular}{|l|l|}
\hline Gender & Percentage \\
\hline Male & 65.1 \\
\hline Female & 34.9 \\
\hline
\end{tabular}

Male preponderance was noted in the study population

Table 4- shows percentage of lung involvement as per gender distribution.

\begin{tabular}{|l|l|l|l|l|}
\hline Gender & $\begin{array}{l}<25 \% \\
\text { involvement }\end{array}$ & $\begin{array}{l}25-50 \% \\
\text { involvement }\end{array}$ & $\begin{array}{l}50-75 \% \\
\text { involvement }\end{array}$ & $\begin{array}{l}>75 \% \\
\text { involvement }\end{array}$ \\
\hline Males & 19.7 & 33.8 & 28.1 & 18.3 \\
\hline Females & 18.4 & 55.2 & 10.5 & 15.7 \\
\hline
\end{tabular}

In males maximum patients had lung involvement between 25- $50 \%$ and followed by $50-75 \%$ involvement.

In females maximum patients had lung involvement between $25-50 \%$ and followed by $<25 \%$ involvement.

Table 5- showing prevalence of pulmonary thromboemb olism in the study population.

\begin{tabular}{|l|l|}
\hline Thromboembolism & Percentage \\
\hline Present & 13.7 \\
\hline Absent & 86.3 \\
\hline
\end{tabular}

Overall $13.7 \%$ patients had pulmonary thromboembolism on CTPA.

Table 6-showing percentage of patients with pulmonary embolism, their age and sex distribution

\begin{tabular}{|l|l|l|l|l|l|l|}
\hline $\begin{array}{l}\text { Pulmonary } \\
\text { embolism }\end{array}$ & Males & Females & 21-40yrs & 41-60yrs & $\begin{array}{l}61- \\
70 y r s\end{array}$ & $\begin{array}{l}71- \\
90 y r s\end{array}$ \\
\hline Present & 16.9 & 7.8 & 18.1 & 23.8 & 5.5 & 0 \\
\hline Absent & 83.1 & 92.2 & 81.9 & 76.2 & 94.5 & 100 \\
\hline
\end{tabular}

Pulmonary thromboembolism was more prevalent in males in comparison to females. Maximum cases of pulmonary thromboembolism were in 41-60 yrs age group followed by $21-40$ yrs.

Table 7- showing percentage of patients with pulmonary thromboembolism with respect to lung involvement

\begin{tabular}{|l|l|l|l|l|}
$\begin{array}{l}\text { Thromboe } \\
\text { mbolism }\end{array}$ & $\begin{array}{l}<25 \% \\
\text { involvement }\end{array}$ & $\begin{array}{l}25-50 \% \\
\text { involvement }\end{array}$ & $\begin{array}{l}50-75 \% \\
\text { involvement }\end{array}$ & $\begin{array}{l}>75 \% \\
\text { involvement }\end{array}$ \\
\hline Present & 0 & 0 & 29.1 & 42.1 \\
\hline Absent & 100 & 100 & 70.9 & 57.9 \\
\hline
\end{tabular}

No cases of pulmonary thromboembolism were found in patients with $<50$ percent lung involvement.

$29.1 \%$ patients with $50-75 \%$ and $42.1 \%$ patients with $>75 \%$ lung involvement had pulmonary thromboembolism.

Pulmonary thromboembolism was the most prevalent in patients having $>75 \%$ lung involvement.

\section{DISCUSSION AND CONCLUSION-}

In our study we included 300 COVID 19 patients who were clinically suspected to have pulmonary thromboembolism and thereby underwent CTPA.

Male preponderance was seen in the study population. Most common age group was 21-40 years followed by 41-60 years. Irrespective of age and gender maximum patients had lung involvement between $25-50 \%$.

Approximately 13.7\% patients had CTPA proven pulmonary thromboembolism. It was more common in males and maximum cases were in 41-60 yrs age group followed by 21 40 yrs.

No cases of pulmonary thromboembolism were found in patients with $<50$ percent lung involvement. $29.1 \%$ patients with $50-75 \%$ and $42.1 \%$ patients with $>75 \%$ lung involvement had pulmonary thromboembolism. Pulmonary thromboembolism was the most prevalent in patients having $>75 \%$ lung involvement. Therefore our study suggests towards a direct relationship between severity of lung involvement on CT and presence of pulmonary thromboembolic phenomenon.

Our study has few limitations. First, it was a retrospective study. Second, correlation with D-dimer levels was not performed.Third, the sample size was limited.

\section{Conflicts of interest-None}

\section{REFERENCES-}

1. Woodard PK. Pulmonary Thromboembolism in COVID-19. Radiology 2021; 298:E107-E108

2. Görlinger K, Dirkmann D, Gandhi A, Simioni P. COVID-19 associated coagulopathy and inflammatory response: what do we know already and what are the knowledge gaps? Anesth Analg 2020; 131(5): 1324-33

3. Danzi GB, Loffi M, Galeazzi G, Gherbesi E. Acute pulmonary embolism and COVID-19 pneumonia: a random association? Eur Heart J 2020;41(19):1858.

4. Wittram C, Maher MM, Yoo AJ, Kalra KM, Shepard JAO, McLoud TC. CT Angiography of Pulmonary Embolism: Diagnostic Criteria and Causes of Misdiagnosis. RadioGraphics 2004;24:1219-38

5. Sakr Y, Giovini M, Leone M, Pizzilli G, Kortgen A, Bauer M et al. Pulmonary embolism in patients with coronavirus disease-2019 (COVID-19) pneumonia: a narrative review. Ann. Intensive Care 2020; 10:124

6. Varga Z, Flammer AJ, Steiger P. Endothelial cell infection and endotheliitis in COVID-19.The Lancet. 2020;395(10234):1417-8. 